\title{
Response of pre-loaded laminate composite plates subject to high velocity impact
}

\author{
S.K. Garcia-Castillo ${ }^{1}$, S. Sánchez-Sáez ${ }^{1}$, E. Barbero ${ }^{1}$ and C. Navarro ${ }^{1}$ \\ 1 Department of Continuum Mechanics and Structural Analysis, Carlos III University of \\ Madrid, Avda. de la Universidad 30, 28911 Leganés, Madrid, Spain \\ e-mail: navarro@ing.uc3m.es
}

\begin{abstract}
An experimental and analytical study of two cases of static preload (uniaxial and biaxial) was made to determine the response of structural plate elements subjected to high velocity impacts under inplane tensile preloading conditions. The results were compared with those obtained in non-preloading specimens. Rectangular specimens were used for the uniaxial and non-preload tests, while cross-shaped specimens were used for the biaxial tests. The impacts were made by spherical projectiles travelling at velocities from 140 to $525 \mathrm{~m} / \mathrm{s}$. As a general result, the existence of a static preloading on the specimen was found to affect the ballistic limit and the damaged area. The biaxial preload specimens showed the higher ballistic limit and the damaged area was slightly bigger in the non-preloaded specimens. From the analytical model, the ballistic limit calculated for the non-loaded specimens showed a difference of $16 \%$ from the experimental values, and in the preloaded specimens the model did not show showed the same tendency as that observed experimentally.
\end{abstract}

\section{INTRODUCTION}

Structural components, such as those commonly used in the aeronautical and aerospace industries, may be subjected to impact loads caused by foreign bodies. An important structural typology is that of pressurized shell structures such as vessels, aircraft fuselages, etc., in which the structural elements are subjected to in-plane loads. This means that to check the structural integrity of such elements under impact loading, the element is considered previously loaded in its plane before receiving a transverse impact load.

In general, there are two types of impact which may originate the failure of the structure, low velocity and high velocity impact. The first type can produce damage that causes a decrease in the mechanical properties without producing catastrophic failure of the structure. High velocity impact can also cause the perforation of the structure, which can affect its structural integrity. Several studies examine the behaviour of structural materials subjected to low velocity impact $[1,2]$ and high velocity impact $[3,4]$, but in these works the specimens were free of load at their edges before testing.

For low velocity impact of preloaded components, several researchers adopt the static loading condition before impact testing, although most of them carry out impact tests on uniaxial preloaded specimens, mainly carbon/epoxy composite laminates [5-9]. This preloading condition does not properly reproduce the complex stress-state that appears in practical structural problems. A few more realistic tests have been made in which the specimens are statically biaxially pre-loaded, although most of the available bibliography is centered on low velocity impacts [10-13].

Very diverse results have been published on the behaviour of preloaded plates subjected to impact, given the great number of parameters that control the impact process, so the subject requires further study. Also most authors have centered on carbon/epoxy laminates subjected to low velocity impact, and much less information is available on woven laminate and glass/polyester material under high velocity impact.

In this study the influence of static tensile uniaxial and biaxial preloading on the behaviour of plates under high velocity impact loading was examined. A plain weave laminate of a glass/polyester material 
is used, comparing the ballistic limit and the extension of the damage in plates with and without preload. An analytical model was used to estimate the ballistic limit in preloaded plates, modifying that proposed initially by Moyre et al. [14] to include the effect of the preload.

\section{EXPERIMENTAL PROCEDURE}

The composite material used in this study was an E-glass fiber/polyester plain weave laminate ( 5 plies) of $3.19 \mathrm{~mm}$ thickness. Two different specimen geometries were used. For non-preloading and uniaxial preloading, rectangular-shaped specimens $(140 \mathrm{~mm} \times 200 \mathrm{~mm})$ were used, whereas crossshaped specimens $(200 \mathrm{~mm} \times 200 \mathrm{~mm}$ ) were used in the tests of biaxial preloading. The geometry and the shape of the latter specimens were selected, after a full-numerical simulation of the problem, in order to get a uniform stress state in the impacted zone.

To keep the specimens pre-loaded during the impact test, a special experimental device was designed and manufactured, and then it was coupled to a gas-cannon set-up. The device allows holding different static loads in two mutually orthogonal directions by two actuators, vertical and horizontal. These actuators may work together or independently. The set-up has a hydraulic device that applies and controls the loads applied to the specimen.

Three types of load were applied on the laminate plates: non preload, tensile uniaxial preload ( $51 \mathrm{kN}$ load applied on the vertical axis), and tensile biaxial preload (51 kN load applied on each axis).

The specimens were impacted by steel spherical projectiles $7.5 \mathrm{~mm}$ in diameter, launched at velocities ranging from $140 \mathrm{~m} / \mathrm{s}$ to $525 \mathrm{~m} / \mathrm{s}$ by a one-stage gas cannon manufactured by SABRE BALLISTIC. During the impact tests, both the projectile striking velocity and the residual velocity were measured by a high speed video camera PHOTRON FASTCAM-ultima APX. After the impact tests, the specimens were inspected by C-Scanning to measure the damage area.

\section{RESULTS AND DISCUSION}

Figures 1.a), 2.a) and 3.a) show the relationships between the impact and residual velocities. Curves were adjusted to the experimental data, consistent with those proposed by Zuckas et al. [15] and then validated, experimentally and numerically, by Kasano [3]. These gave:

$$
V_{r}=\left\{\begin{array}{cc}
0 \quad, 0<V_{i} \leq V_{l} \\
A \cdot\left(V_{i}^{p}-V_{l}^{p}\right)^{1 / p} & , V_{i}>V_{l}
\end{array}\right.
$$

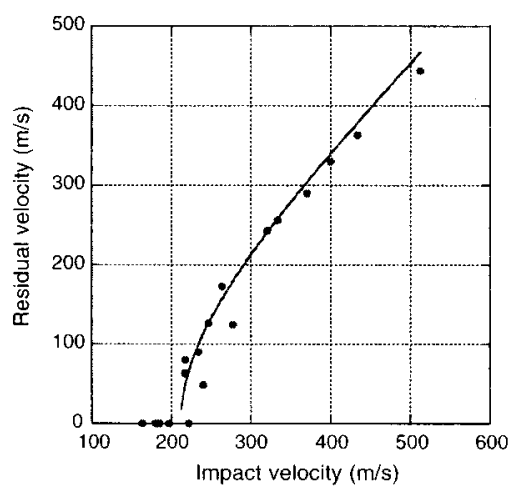

a)

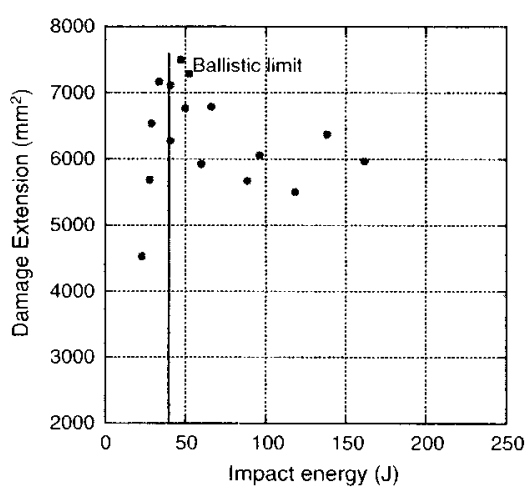

b)

Figure 1. Non preloading specimens a) residual velocity versus impact velocity and b) damage area versus impact energy. 


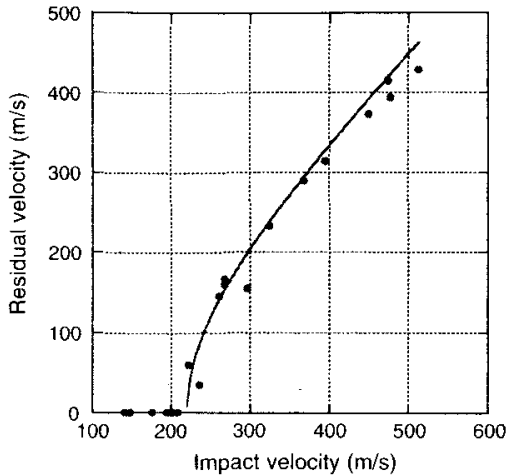

a)

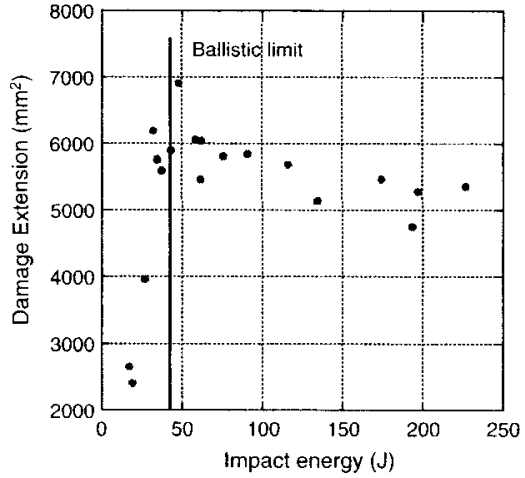

b)

Figure 2. Uniaxial preloading specimens a) residual velocity versus impact velocity and b) damage area versus impact energy.

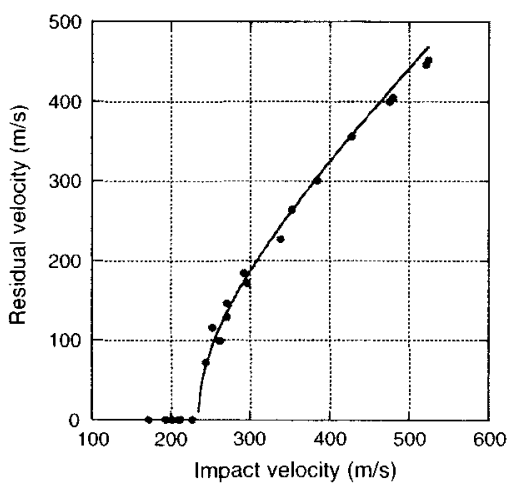

a)

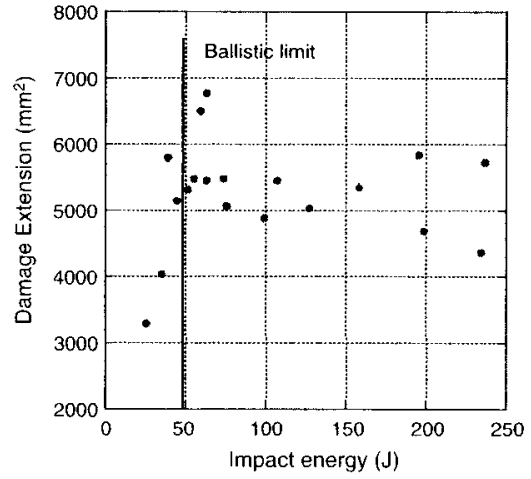

b)

Figure 3. Biaxial preloading specimens a) residual velocity versus impact velocity and b) damage area versus impact energy.

where: $V_{r}$ is the residual velocity, $V_{i}$ the impact velocity, $V_{l}$ the ballistic limit, and $p$ and $A$ are two empirical adjusting parameters.

From the mathematical expressions of the curves, the ballistic limits were obtained. In the nonpreloading test, the ballistic limit was $211 \mathrm{~m} / \mathrm{s}$, whereas in the uniaxial preloading case it was $220 \mathrm{~m} / \mathrm{s}$ and in the biaxial one it was $234 \mathrm{~m} / \mathrm{s}$. A slight increment is observed in the ballistic limits in preloaded specimens, of $11 \%$ in the biaxial preloaded plates. These values were compared with those of an analytical model based on that developed by Morye et al. [14] for non preloading plates, and modified in this study to include the effect of the preload and the area damaged by delamination. The ballistic limit can be calculated from the equation:

$$
V_{l}=\sqrt{\frac{2}{m} \cdot E_{T}}
$$

Where ET is the energy absorbed by the plate, equation 3. For the calculation of ET in addition of the three mechanisms of energy absorption proposed by Moyre et al. [14]: tensile failure o the primary yarns (ETF, equation 4), elastic deformation of the secondary yarns (EED, equation 7), and the kinetic 
energy of the moving portion of the composite panels (EKE, equation 8), a term due to the damage by delamination (EDL, equation 9) was adopted.

$$
\begin{gathered}
E_{T}=E_{T F}+E_{E D}+E_{K E}+E_{D L} \\
E_{T F}=4 \cdot E_{C} \cdot R_{C} \cdot D \cdot h
\end{gathered}
$$

where: $E_{C}$ is the energy absorbed at the point of tensile failure of the material per unit volume, $R_{c}$ is the radius of the cone formed on the rear side of the plate, $D$ the diameter of the projectile and $h$ the specimen thickness. The radius of the cone is calculated by equation 5 :

$$
R_{c}=t \cdot V_{t}
$$

where: $t$ is the residence time of the projectile in the plate and $V_{t}$ the velocity of the transversal wave. To calculate $V$, equation 6 was used.

$$
V_{t}=\sqrt{\frac{\left(1+\varepsilon_{p}\right) \cdot \sigma_{p}}{\rho}}-\int_{\varepsilon_{i}}^{\varepsilon_{p}} \sqrt{\frac{E}{\rho}} d \varepsilon
$$

where: $\epsilon_{p}$ is the failure strain of the composite, $\epsilon_{i}$ the initial strain (zero in the non-preload specimen and 0.01127 in the preload specimen), $\sigma_{p}$ is the failure stress of the composite, $\rho$ is the density of the composite and $E$ is the tensile modulus of the composite.

$$
\begin{gathered}
E_{E D}=4 \cdot E \cdot \varepsilon_{p}^{2} \cdot h \cdot \pi \cdot \int_{D / 2}^{R_{c}}\left(\frac{R_{c}-r}{2 \cdot R_{c}-D}+\varepsilon_{i}\right)^{2} \cdot r \cdot d r \\
E_{K E}=\frac{1}{2} \cdot R_{c} \cdot V_{c}^{2} \cdot \pi \cdot h \cdot \rho
\end{gathered}
$$

where: $V_{c}$ is the velocity of the cone assumed to be equal to the residual projectile velocity.

$$
E_{D L}=P \cdot \pi \cdot\left(\frac{d}{2}\right)^{2} \cdot A_{q I} \cdot G_{I I C}
$$

where: $P$ is the percent delaminating layers, $d$ is the diameter of the damage area, $A_{q l}$ is the quasilemniscate area reduction and $G_{I I C}$ is the critical dynamic strain energy release rate in mode II.

The properties of the material and parameters used in the model, Table 1, were taken from experimental tests and from the literature.

In Table 2 the ballistic limits corresponding to the model compared with the experimental data are shown.

The ballistic limits calculated with the analytical model present a minimum difference betweenamong the nonload and the preloaded specimens, since the modification introduced in the model

Table 1. Properties and parameters used in the analytical model.

\begin{tabular}{|c|c|c|c|c|c|c|c|}
\hline & $\rho\left(\mathrm{kg} / \mathrm{m}^{3}\right)$ & $\sigma_{\mathrm{p}}(\mathrm{MPa})$ & $\varepsilon_{\mathrm{p}}$ & $\mathrm{E}(\mathrm{GPa})$ & $\mathrm{G}_{\mathrm{IIC}}\left(\mathrm{kJ} / \mathrm{m}^{2}\right)$ & $\mathrm{P}$ & $\mathrm{A}_{\mathrm{ql}}$ \\
\hline Value & 1980 & 367.39 & 0.03568 & 10.13 & 2.8 & $100 \%$ & 1 \\
\hline
\end{tabular}

Table 2. Ballistic limit $(\mathrm{m} / \mathrm{s})$.

\begin{tabular}{|l|c|c|c|}
\hline Load case & Experimental & Analytical & Difference \% \\
\hline Non preload & 211 & $178 \pm 11$ & $16 \%$ \\
\hline Uniaxial preload & 220 & $176 \pm 13$ & $20 \%$ \\
\hline Biaxial preload & 234 & $175 \pm 6$ & $25 \%$ \\
\hline
\end{tabular}


has no significant influence on the energy of deformation of the secondary fibers and in the energy of tensile failure of the primary fibers. Comparing the experimental ballistic limit with that obtained from the analytical model, differences of $16 \%$ in the case of the non-preloaded specimens were observed, and slightly greater for the preloaded specimens (unixial and biaxial), Table 2 . The variability of the results of the models makes it difficult to establish a tendency in the behaviour of the ballistic limit.

These differences could be due to the use of static mechanical properties in the modelling of a dynamic phenomenon, since the properties of the glass fiber are strain rate dependent [16]. The use of dynamic properties would improve the results of the model. It could also be improved by the incorporation of additional mechanisms of energy absorption, such as that absorbed by matrix cracking.

Figures 4, 5 and 6 show the images of the C-Scanning inspection. These figures reveal that at similar impact velocities, the damage area is greater in the non-preload specimens than in the uniaxially preloaded and the biaxially preloaded specimens. This could be because an increment in the existing preload produces a reduction of the time of contact and the deflection of the impact point of the specimen, decreasing to the existence of the bending phenomena responsible for the appearance and extension of the damage.

From the images of C-scan, the damaged area produced by delamination was calculated in the impacted specimens. Figures 1.b), 2.b) and 3.b) show the damaged area versus the impact energy. In these figures the value of the energy corresponding to the ballistic limit was represented to show the different tendencies in the damaged area before and after reaching that velocity. The behaviour is similar in the three cases of load. The damaged area grows quickly in roghly linear form when the impact energy increases until the energy at the ballistic limit is reached. At impact velocities above the ballistic limit, the damaged area decreases, adjusting the values to a curve function of the inverse of the impact energy,

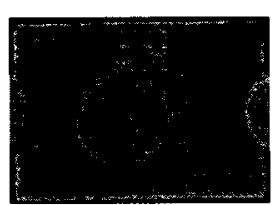

a)

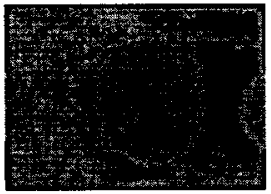

b)

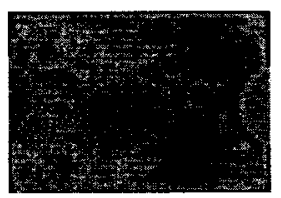

c)

Figure 4. C-Scan images of the non preloaded plates at impact velocities: a) $163 \mathrm{~m} / \mathrm{s}$, b) $233 \mathrm{~m} / \mathrm{s}$ and c) $443 \mathrm{~m} / \mathrm{s}$.

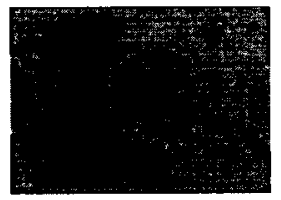

a)

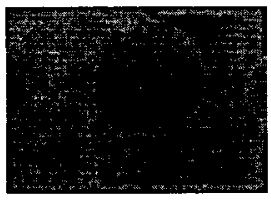

b)

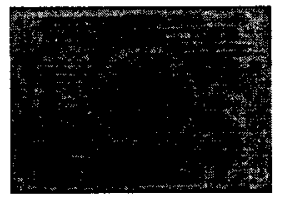

c)

Figure 5. C-Scan images of uniaxial preloaded plates at impact velocities: a) $176 \mathrm{~m} / \mathrm{s}$, b) $236 \mathrm{~m} / \mathrm{s}$ and c) $513 \mathrm{~m} / \mathrm{s}$.

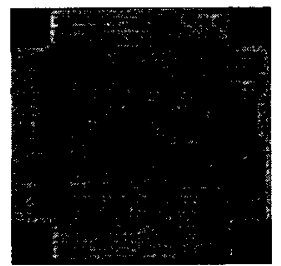

a)

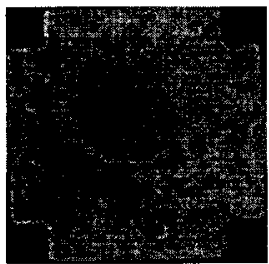

b)

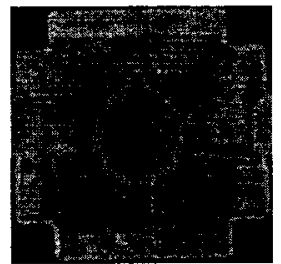

c)

Figure 6. C-Scan images of biaxial preloaded plates at impact velocities: a) $171 \mathrm{~m} / \mathrm{s}$, b) $261 \mathrm{~m} / \mathrm{s}$ and c) $521 \mathrm{~m} / \mathrm{s}$. 
tending asymptotically to a constant value. This could be because when the plate is not perforated, all the impact energy is absorbed in the form of damage, so an increment of this energy implies a greater damaged area. Beyond the ballistic limit, the behaviour is the opposite, since most of the impact energy is used in accelerating the plate, to the detriment of the damage mechanisms. This had been observed by other researchers in non preloading specimens $[17,18]$. The equation that fits the behaviour of damage area as a function of the impact energy is presented next:

$$
A_{d}=\left\{\begin{array}{lc}
n_{o}+m_{o} \cdot E_{i}, & E_{i} \leq E_{l} \\
n_{1}+m_{1} \cdot \frac{1}{E_{i}}, & E_{i}>E_{l}
\end{array}\right.
$$

where $A_{d}$ is the damaged area, $E_{i}$ the impact energy, $E_{l}$ the energy at ballistic limit, and $n_{o}, m_{o}, n_{1}$ and $m_{1}$ are adjusting parameters.

The results show good correlation with the impact energy as shown in Table 3, worse in the biaxial than in the other load cases, since a greater dispersion exists in the values of the damaged area.

Table 3. Correlation factors of adjusting curves using equation 10 .

\begin{tabular}{|l|c|c|}
\hline Load case & $\mathbf{R}^{2}$ - below the ballistic limit $\left(\mathbf{E}<\mathbf{E}_{\mathrm{L}}\right)$ & $\mathbf{R}^{2}$ - Above the ballistic limit $\left(\mathbf{E}>\mathbf{E}_{\mathrm{L}}\right)$ \\
\hline Non preload & 0.94 & 0.67 \\
\hline Uniaxial preload & 0.90 & 0.55 \\
\hline Biaxial preload & 0.69 & 0.36 \\
\hline
\end{tabular}

\section{CONCLUSIONS}

The influence of the preload conditions (uniaxial and biaxial) on the behaviour of plates made of woven glass/polyester composite laminate materials under impact load. The residual velocity, the ballistic limit and the damage extension was obtained.

The damaged area follows the same tendencies in the preloaded specimens as in the non preloaded. The damaged area grows linearly with increased impact energy until the ballistic limit is reached, beyond which the damaged area decreases, adjusting the values to a curved function of the inverse of the impact energy, tending asymptotically to a constant value.

In the specimens of composite material biaxially loaded, the ballistic limit of the projectile is higher and the damage area lower than those obtained with the uniaxial and non preloading specimens.

The analytical model for the determination of the ballistic limit does not show the tendency observed experimentally. The differences between the values of the ballistic limit experimentally obtained and those of the analytical model could be reduced by using the dynamic properties of the material and considering additional mechanisms of energy absorption, such as matrix cracking.

\section{Acknowledgments}

The authors are indebted to the Comisión Interministerial de Ciencia y Tecnología from Spain (Project MAT20010735) for the financial support of this work.

\section{References}

[1] Cantwell W.J., Morton J., Composite 20 (1989) 545-551.

[2] Richardson M.O.W., Wisheart M.J., Compos part A -Appl S 27 (1996) 1123-1131.

[3] Kasano H., JSME Int J-serie A 42 (1999) 147-157.

[4] Nunes L.M., Paciornik S., D’Almeida J.R.M., Compos Sci Technol 64 (2004) 945-954. 
[5] Sankar, BV and Sun, CT., "Low-velocity impact damage in graphite-epoxi laminates subjected to tensile initial stresses". AIAA Journal 24 (1986) 470-471.

[6] Nettles A, Vince D. and Branscomb C., "The effects of tensile preloads on the impact response of carbon/epoxy laminates", 40 ${ }^{\text {th }}$ International SAMPE Symposium, (1995) 1019-1025.

[7] Chiu S-T., Liou Y-Y., Chang Y-C., Ong C-L., Mater Chem Phys 47 (1997) pp. 268-272.

[8] Kelkar A.D., Sankar A.D., Rakeev K., Ashenbrenner R.J., AIAA Journal 98 (1998) 1978-1987.

[9] Zhang X., Davies G.A.O., Hitchings D., Int J Impact Eng 22 (1999) 485-509.

[10] Robb M.D., Arnold W.S. and Marshall I.H., Compos Struct 32 (1995) 141-149.

[11] Whittingham B., Marshall I.H., Mitrevski T. and Jones R., Compos Struct 66 (2004) 685-698.

[12] McGowan D.M., Ambur D.R., J Aircraft 36 (1999) 596-602.

[13] Khalili SMR., Mittal RK., Panah NM., Compos Struct (2006) Article in press.

[14] Moyre S.S., Hine P.J., Duckett R.A.; Carr D.J. and Ward I.M.; Compos Sci Tecnol 60 (2000) 2631-2642.

[15] Zukas J.A., Nicholas T., Swift H., Greszczuk L.B., Curran D.R., Impact Dynamic, Krieger Publishing Company, Florida, USA, (1992).

[16] Harding J and Ruiz C., Key Eng Mat 131-143 (1998) 403-426.

[17] Will M.A., Franz T., Nurik G.N., Compos Struct 58 (2002) 259-270.

[18] Lopez-Puente J. "Análisis y modelización de impactos de alta velocidad sobre laminados carbono/epoxi", PHD Thesis, 2003 In spanish. 